\title{
Tingkat Ketepatan Audiometer Skrining Medan Bebas untuk Mendeteksi Gangguan Dengar Anak Sekolah Dasar dengan Otitis Media
}

\author{
Widya W. Hartanto, Thaufiq S. Boesoirie, Ratna A. S. Poerwana \\ Departemen Ilmu Kesehatan Telinga Hidung Tenggorok Bedah Kepala \& Leher \\ Fakultas Kedokteran Universitas Padjadjaran-Rumah Sakit Dr. Hasan Sadikin Bandung
}

\begin{abstract}
Abstrak
Skrining pendengaran pada anak sekolah dapat mengetahui lebih dini gangguan dengar akibat otitis media sehingga hasil pengobatannya akan lebih baik. Audiometer skrining medan bebas merupakan alat skrining pendengaran yang sederhana, terjangkau, ringkas, mudah dan singkat, tetapi belum diukur tingkat ketepatannya untuk anak sekolah dasar. Penelitian ini bertujuan untuk menguji tingkat ketepatan audiometer skrining medan bebas untuk mendeteksi gangguan dengar pada anak sekolah dasar yang menderita otitis media. Penelitian uji diagnostik dengan rancangan penelitian potong silang dilakukan di Sekolah Dasar Sejahtera dan Poliklinik Departemen Ilmu Kesehatan Telinga Hidung Tenggorok-Bedah Kepala dan Leher RS Dr. Hasan Sadikin Bandung periode bulan Juni-Agustus 2011. Dari 479 anak sekolah dasar, didapatkan 86 subjek sesuai kriteria inklusi. Terdapat gangguan dengar pada 56 anak yang diperiksa audiometer skrining medan bebas dan 51 anak yang diperiksa audiometri nada murni. Hasil uji diagnostik audiometer skrining medan bebas didapatkan sensitivitas 90,2\%; spesifisitas 71,4\%; indeks Kappa 0,630. Perbandingan pemeriksaan pendengaran antara audiometri skrining medan bebas dan audiometri nada murni didapatkan $\mathrm{p}=0,302$. Simpulan, tingkat ketepatan audiometer skrining medan bebas sama dengan audiometer nada murni untuk mendeteksi gangguan dengar anak sekolah dasar yang menderita otitis media. [MKB. 2013;45(1):62-8]
\end{abstract}

Kata kunci: Audiometer skrining medan bebas, otitis media, skrining pendengaran

\section{Accuracy of Portable Screening Audiometer for Detecting Hearing Loss in Elementary School Children with Otitis Media}

\begin{abstract}
Hearing skrining in school children can detect hearing loss due to otitis media earlier therefor treatment will give better outcome. Portable screening audiometer is a device which are simple, less expensive, brief, easy to use and has shorter examination time but has not been measured its accuracy for hearing screening in elementary school children. The objective of this study was to measure the accuracy of portable screening audiometry for detecting hearing loss in elementary school children with otitis media. A diagnostic test study with cross-sectional method was conducted at Sejahtera Elementary School and at Out-patient Clinic Otorhinolaryngology-Head and Neck Department Dr. Hasan Sadikin Hospital Bandung period June until August 20011. From 479 children, there were 86 children match with inclusion criteria. Hearing loss was found in 56 children examined using portable screening audiometer and in 51 children using pure tone audiometry. Diagnostic test result for portable screening audiometer were $90.2 \%$ sensitivity, $71.4 \%$ specificity, with Kappa index 0.630 and p value was 0.302 compared to pure tone audiometry. In conclusion, the accuracy of portable screening audiometer is as good as pure tone audiometry in order to detect hearing loss in elementary school children with otitis media. [MKB. 2013;45(1):62-68]
\end{abstract}

Key words: Hearing screening, otitis media, portable screening audiometry

Korespondensi: Widya Wicaksono Hartanto, dr., Departemen Ilmu Kesehatan Telinga Hidung Tenggorok Bedah Kepala \& Leher, Fakultas Kedokteran Universitas Padjadjaran-Rumah Sakit Dr. Hasan Sadikin, jalan Pasteur No. 38 Bandung, mobile 08122188877,e-mailweehart@yahoo.com 


\section{Pendahuluan}

Gangguan dengar terjadi pada $6 \%$ populasi dunia, diperkirakan oleh World Health Organization (WHO) sebanyak 62 juta orang usia $<15$ tahun akan mengalami gangguan dengar dan $50 \%$ kejadian gangguan dengar ini dapat dicegah. ${ }^{1-3}$ Prevalensi gangguan dengar di Indonesia dilaporkan sebesar $4,2-9,2 \%{ }^{4,5}$ Penyebab gangguan dengar adalah sumbatan serumen sebanyak $13,2 \%$; otitis media serosa $0,3 \%$; perforasi membran timpani yang kering 2,6\%; dan otitis media supuratif kronik (OMSK) sebanyak 3,2\%. ${ }^{5}$

Otitis media menunjukkan prevalensi sebesar $13,2 \%,{ }^{6}$ merupakan penyakit infeksi yang paling sering menyebabkan gangguan dengar konduktif sementara pada anak usia sekolah. Angka kejadian gangguan dengar pada anak sekolah dengan otitis media adalah $57 \%{ }^{7}$ di Australia dan $75,38 \%{ }^{8}$ dari tersangka otitis media di Indonesia.

Agar dapat merujuk penderita ke rumah sakit rujukan atau dokter spesialis Telinga Hidung Tenggorok-Bedah Kepala dan Leher (THT-KL) sangat diperlukan deteksi dini agar mendapatkan pengobatan secepat-cepatnya. Saat ini audiometer nada murni merupakan pemeriksaan baku emas untuk dapat mendeteksi gangguan dengar pada anak usia sekolah, ${ }^{2}$ tetapi distribusi audiometer nada murni di Indonesia terbatas hanya di rumah sakit rujukan. Alat ini masih merupakan produk luar negeri yang mahal harganya, sehingga perlu dicari alat lain yang lebih murah.

Saat ini terdapat audiometer skrining medan bebas dengan harga yang terjangkau, sederhana, ringkas, mudah, waktu pemeriksaan 15-20 menit, dan dapat diandalkan dengan hasil uji diagnostik pada anak balita memberikan hasil sensitivitas $90,9 \%$ dan spesifisitas $68,4 \% .{ }^{9}$ Permasalahannya alat ini belum diukur tingkat ketepatannya untuk mendeteksi gangguan dengar pada anak sekolah dasar agar dapat digunakan sebagai alat skrining pendengaran. Alat yang bersangkutan diharapkan memberikan hasil lebih baik karena pemeriksaan pendengaran pada anak sekolah dasar memberikan respons yang lebih baik terhadap stimulus suara yang diberikan bila dibandingkan dengan anak balita. Diharapkan pemeriksaan mempergunakan alat deteksi dengar ini dapat menunjang program dari Komite Nasional Penanggulangan Gangguan Pendengaran dan Ketulian (KOMNAS PGPKT) dan program Sound Hearing 2030. Cara skrining pendengaran yang dilakukan di sekolah mampu menurunkan kejadian gangguan dengar yang dapat dihindari sebesar 50\% tahun 2015 dan $90 \%$ pada tahun 2030. Oleh sebab itu, maka dilakukan penelitian dengan tujuan untuk dapat mengetahui ketepatan audiometer skrining medan bebas dalam mendeteksi gangguan dengar pada anak sekolah dasar yang menderita otitis media dibandingkan dengan baku emas (audiometri nada murni).

\section{Metode}

Subjek merupakan anak sekolah dasar yang sesuai dengan kriteria inklusi dan juga orangtua bersedia anaknya ikut dalam penelitian (informed consent). Subjek penelitian ini memenuhi kriteria inklusi, yaitu anak yang duduk di bangku sekolah dasar, menderita otitis media, dan bersedia melepaskan alat bantu mendengar pada saat pemeriksaan jika sudah memakai alat bantu mendengar. Kriteria eksklusi pada penelitian ini, yaitu anak yang tidak dapat dilakukan pemeriksaan audiometri nada murni, menderita penyakit kelainan kranio-fasial (seperti kelainan bentuk daun atau liang telinga, kelainan langit-langit mulut), menderita penyakit kelainan kongenital, terdapat infeksi atau riwayat infeksi susunan saraf seperti meningitis, terdapat riwayat trauma kepala, dan riwayat penggunaan obat ototoksik.

Penelitian ini adalah uji diagnostik dengan rancangan penelitian secara potong lintang serta memakai audiometri nada murni sebagai baku emas. Besar sampel ditentukan berdasarkan taraf kepercayaan 95\% dengan taksiran sensitivitas 90\% dan presisi (kesalahan menaksir) kurang lebih $10 \%$. Besar sampel minimal 66 orang dari rumus besar sampel untuk menaksir proporsi populasi.

Penelitian ini sudah memperoleh persetujuan dari Komite Etik Penelitian Fakultas Kedokteran Universitas Padjadjaran Bandung, dilakukan pada bulan Juni-Agustus 2011. Anamnesis dilakukan untuk mengetahui gejala dan tanda otitis media. Pemeriksaan fisis meliputi status kesadaran dan kondisi umum subjek, juga pemeriksaan otoskopi mempergunakan otoskop pneumatik. Otitis media didiagnosis berdasarkan anamnesis, pemeriksaan fisis, dan pemeriksaan otoskopi.

Semua subjek yang memenuhi kriteria inklusi dilakukan pemeriksaan dengan mempergunakan audiometer skrining medan bebas di salah satu ruangan kelas berukuran $6 \times 4 \mathrm{~m}$ yang diatur tata letaknya di Sekolah Dasar Sejahtera Bandung dengan bising lingkungan sebesar 19,875 dbHL dan juga dilakukan pemeriksaan audiometer nada murni pada hari yang sama di Ruang Audiologi Klinik Gangguan Dengar dan Bicara Subbagian Audio-Vestibular Departemen Ilmu Kesehatan Telinga Hidung Tenggorok-Bedah Kepala dan Leher Rumah Sakit Dr. Hasan Sadikin Bandung.

Pemeriksaan audiometer ini dilakukan dengan tahapan: pemeriksaan dilakukan di sekolah dalam ruangan yang mempunyai ambient noise sebesar $<40 \mathrm{~dB} .{ }^{10}$ Posisi subjek duduk berhadapan dengan 

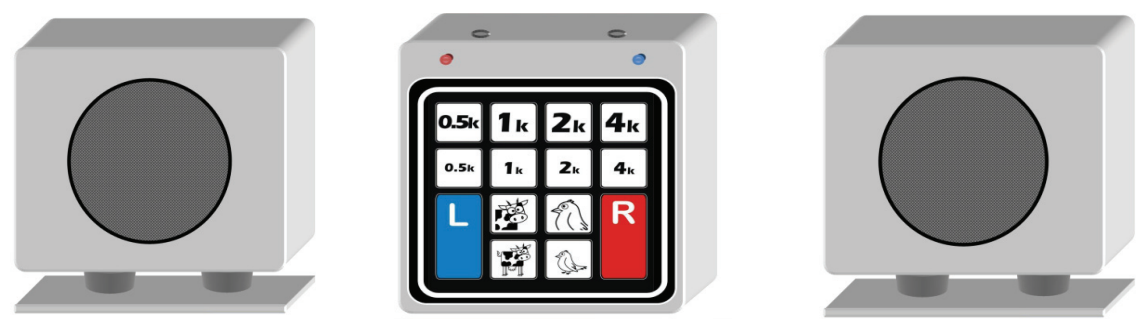

Gambar 1 Audiometer Skrining Medan Bebas

pemeriksa (duduk sendiri atau dipangku orangtua atau wali) dan posisi kursi subjek satu meter dari speaker kanan dan speaker kiri. Subjek diberikan instruksi untuk mengangkat tangan kiri apabila mendengar suara dari pengeras suara kiri atau mengangkat tangan kanan bila mendengar suara dari pengeras suara kanan. Orangtua diminta agar tidak memberikan reaksi pada saat anak diberikan stimulus suara. Pemeriksa akan menekan tombol pada modul utama alat tersembunyi yang berada di bawah meja dan juga mengamati serta mencatat reaksi dari subjek. Stimulus (percakapan, warble, atau bising pita sempit) bernada diberikan, yang pertama dites adalah frekuensi $500 \mathrm{~Hz}$ dan 2.000 Hz. Jika anak masih kooperatif, tes dilanjutkan dengan frekuensi $1.000 \mathrm{~Hz}$ dan $4.000 \mathrm{~Hz}$. Amati respons anak yang diperiksa. Interval waktu antara tiap stimulus harus bervariasi untuk menghindari pola yang dapat ditebak. Sangat penting untuk mengamati respons ketika tidak ada stimulus yang diberikan. Jika terdapat keragu-raguan, sebaiknya menaikkan intensitas sampai muncul reaksi yang jelas. Respons pemeriksaan dinyatakan valid jika subjek menunjukkan respons terhadap stimulus nada dengan jelas/gamblang. Jika respons yang terjadi ragu-ragu atau tidak merespons terhadap stimulus suara yang diberikan maka pemeriksaan pada intensitas dan frekuensi yang sama diulang hingga dua-tiga kali untuk memastikan respons yang terjadi benar-benar akibat stimulus suara yang diberikan. ${ }^{9}$

Untuk mendapatkan ambang dengan hantaran udara dan hantaran tulang, dilakukan pemeriksaan audiometer nada murni pada frekuensi $500 \mathrm{~Hz}$, $1.000 \mathrm{~Hz}, 2.000 \mathrm{~Hz}$, dan $4.000 \mathrm{~Hz}$.

Hasil pemeriksaan menggunakan audiometer skrining medan bebas hanya 2, yaitu pendengaran normal dan terganggu. Dilakukan uji diagnostik dengan menghitung sensitivitas, spesifisitas, nilai duga positif dan negatif, serta indeks Kappa. Pada penelitian ini juga dilakukan uji chi-kuadrat, Exact Fisher, dan McNemar memakai program Statistical Package for Social Sciences (SPSS) versi 13 dengan kemaknaan hasil uji ditentukan berdasarkan nilai $\mathrm{p}<0,05$.

\section{Hasil}

Telah dilakukan pemeriksaan terhadap 479 anak sekolah dasar. Dari 479 anak tersebut didapatkan 86 anak yang menderita otitis media, kemudian dilakukan pemeriksaan pada kedua telinga anak tersebut sehingga jumlah telinga yang diperiksa sebanyak 172 telinga (Tabel 1).

Diagnosis terbanyak pada subjek penelitian ini yaitu otitis media efusi $(89 \%)$ dan terbanyak pada laki-laki (52\%). Rasa penuh di dalam telinga merupakan keluhan yang paling banyak dialami penderita (48\%) dan seperempat penderita tidak terdapat keluhan saat dilakukan anamnesis (Tabel 2). Secara statistik tidak terdapat perbedaan hasil pemeriksaan pendengaran yang bermakna antara audiometer skrining medan bebas dan audiometri nada murni (Tabel 3).

Audiometer skrining medan bebas penderita menunjukkan hasil sensitivitas $90,2 \%$; spesifisitas $71,4 \%$; nilai duga positif $82,1 \%$; nilai duga negatif $83,3 \%$; akurasi $82,6 \%$; rasio kemungkinan positif 3,15 ; rasio kemungkinan negatif 0,14 ; dan nilai indeks Kappa 0,630 (Tabel 4). Terdapat hasil normal pada pemeriksaan audiometer skrining medan bebas tetapi gangguan pendengaran pada pemeriksaan audiometer nada murni hanya pada

\section{Tabel 1 Karakteristik Subjek}

\begin{tabular}{lcc}
\hline \multicolumn{1}{c}{ Karakteristik } & $\begin{array}{c}\text { Jumlah } \\
(\mathbf{n = 8 6 )}\end{array}$ & $\mathbf{\%}$ \\
\hline $\begin{array}{l}\text { Diagnosis } \\
\quad \text { Otitis media supuratif }\end{array}$ & 3 & 4 \\
$\quad \begin{array}{l}\text { kronik } \\
\text { Otitis media efusi }\end{array}$ & 77 & 89 \\
$\quad \begin{array}{l}\text { Membran timpani } \\
\text { perforasi tenang }\end{array}$ & 6 & 7 \\
Jenis kelamin & & \\
$\quad$ Laki-laki & 45 & 52 \\
Perempuan & 41 & 48 \\
\hline
\end{tabular}


Tabel 2 Keluhan Subjek Penelitian

\begin{tabular}{lcc}
\hline \multicolumn{1}{c}{ Keluhan } & $\begin{array}{c}\text { Jumlah } \\
(\mathbf{n = 8 6})\end{array}$ & $\mathbf{\%}$ \\
\hline Gangguan mendengar & 16 & 19 \\
Rasa penuh di telinga & 41 & 48 \\
Keluar cairan dari telinga & 1 & 1 \\
Telinga berdenging & 2 & 2 \\
Gendang telinga berlubang & 4 & 5 \\
Tanpa keluhan & 22 & 25 \\
\hline
\end{tabular}

penderita otitis media yang unilateral sebanyak 5 subjek (Tabel 5).

\section{Pembahasan}

Penelitian Georgalas dkk.. ${ }^{11}$ Grundfast dkk..${ }^{12}$ dan $\mathrm{WHO}^{2}$ pada anak sekolah dasar, OME merupakan penyebab gangguan dengar yang paling banyak ditemukan. Pada penelitian diagnosis OME juga paling banyak ditemukan (Tabel 1).

Perbandingan antara laki-laki dan perempuan mendekati 1:1 sehingga hasil uji dapat dianggap mewakili kedua jenis kelamin (Tabel 1). Hasil ini tidak terlalu jauh berbeda dengan penelitian skrining pendengaran dan otitis media pada anak sekolah yang dilakukan oleh Georgalas dkk., ${ }^{11}$ yaitu didapatkan perbandingan laki-laki dengan perempuan 1,08:1 serta perbandingan penelitian Ratunanda ${ }^{8}$ pada anak kelas satu tersangka OME di beberapa sekolah dasar kota Bandung dengan perbandingan 1,5:1.

Keluhan gangguan mendengar terdapat pada 19\% subjek (Tabel 2), akan tetapi secara statistik tidak bermakna. Keadaan ini kemungkinan oleh karena terdapat fluktuasi gangguan dengar yang berhubungan dengan otitis media seperti yang dikemukakan oleh Langan dkk. ${ }^{13}$ atau kesulitan saat anamnesis terhadap anak untuk menentukan apakah gangguan dengar memang terjadi karena sering kali anak merasa ada gangguan padahal kenyataannya tidak ada. Oleh karena itu, dalam evaluasi, konfirmasi kepada orangtua atau guru merupakan hal yang penting. ${ }^{14}$ Kondisi berbeda ditemukan pada kelompok dengan keluhan rasa penuh di telinga atau gendang telinga berlubang yang bermakna secara statistik terhadap kejadian gangguan dengar. Keadaan ini dapat dijadikan masukan bagi para klinisi untuk kecurigaan kuat gangguan dengar jika ada keluhan telinga terasa penuh atau gendang telinga berlubang penderita otitis media. Pada penelitian ini tidak didapatkan keluhan yang cukup tinggi pada saat dilakukan anamnesis, hal ini sesuai dengan penelitian oleh Ratunanda ${ }^{8}$ yang mendapatkan hasil bahwa hanya $1,54 \%$ anak tersangka OME mempunyai keluhan, sedangkan sisanya tanpa keluhan apapun. Hal ini memperlihatkan bahwa sering kali anak dengan OME tidak memberikan keluhan apapun.

Pada hasil uji diagnostik didapatkan tingkat ketepatan audiometer skrining medan bebas yang divalidasi dengan hasil pemeriksaan audiometri nada murni menunjukkan angka yang memenuhi syarat untuk kepentingan skrining. ${ }^{15}$

Hasil uji diagnostik dikatakan positif kuat bila nilai rasio kemungkinan $>1$ dan negatif kuat bila nilai rasio kemungkinan mendekati 0 . Dari hasil penelitian berdasarkan nilai rasio kemungkinan positif hasil uji diagnostik yang positif kuat tetapi belum memberikan nilai diagnostik yang baik..$^{15}$

Penelitian ini merupakan penelitian yang baru pertama kali dilakukan. Penelitian sebelumnya telah dilakukan oleh Yusuf, ${ }^{9}$ yaitu mengenai uji diagnostik audiometer skrining medan bebas pada anak balita dengan baku emas pemeriksaan pendengaran yang menggunakan brain evoked response audiometry (BERA). Hasil penelitian ini tidak jauh berbeda dengan penelitian Yusuf ${ }^{9}$ yang memberikan sensitivitas audiometer skrining medan bebas sebesar $90,91 \%$ serta spesifisitas $68,42 \%$. Walaupun diharapkan pada penelitian ini memberikan hasil yang jauh lebih baik karena subjek lebih kooperatif bila dibandingkan dengan subjek penelitian Yusuf ${ }^{9}$ yaitu balita, akan tetapi

Tabel 3 Hubungan Hasil Pemeriksaan Pendengaran Audiometer Skrining Medan Bebas dengan Pemeriksaan Audiometri Nada Murni pada Anak Sekolah Dasar yang Menderita Otitis Media

\begin{tabular}{lcccc}
\hline \multirow{2}{*}{$\begin{array}{c}\text { Audiometri Skrining } \\
\text { Medan Bebas }\end{array}$} & \multicolumn{4}{c}{ Audiometri Nada Murni } \\
\cline { 2 - 5 } & Terganggu & Normal & Jumlah & p \\
\hline Terganggu & 46 & 10 & 56 & $0,302^{*}$ \\
Normal & 5 & 25 & 30 & \\
Jumlah & 51 & 35 & 86 & \\
\hline
\end{tabular}

Keterangan: * Uji McNemar 
Tabel 4 Hasil Uji Diagnostik Audiometer Skrining Medan Bebas

\begin{tabular}{lcc}
\hline \multicolumn{1}{c}{ Analisis } & Penghitungan & Hasil \\
\hline Positif benar & $46 / 86$ & $53,5 \%$ \\
Negatif benar & $25 / 86$ & $29,1 \%$ \\
Nilai akurasi diagnostik & $(46+25) / 86$ & $82,6 \%$ \\
Sensitivitas & $46 /(46+5)$ & $90,2 \%$ \\
Negatif semu & $5 /(46+5)$ & $10 \%$ \\
Spesifisitas & $25 /(25+10)$ & $71,4 \%$ \\
Positif semu & $10 /(25+10)$ & $28,6 \%$ \\
Nilai duga positif & $46 /(46+10)$ & $82,1 \%$ \\
Nilai duga negatif & $5 /(5+25)$ & $83,3 \%$ \\
Rasio kemungkinan positif & $90,2 \% /(1-71,4 \%$ & 3,15 \\
Rasio kemungkinan negatif & $(1-90,2 \%) / 71,4 \%$ & 0,14 \\
Indeks Kappa & $2(1.100-50) /(56 \times 35)+(30 \times 51))$ & 0,630 \\
\hline
\end{tabular}

sensitivitas yang dihasilkan tidak jauh berbeda. Perbedaan yang terlihat yaitu nilai spesifisitasnya lebih baik bila dibandingkan dengan penelitian Yusuf. ${ }^{9}$ Sensitivitas audiometer skrining medan bebas tidak jauh berbeda dengan audiometri nada murni sebagai alat skrining pendengaran pada anak sekolah. Penelitian Halloran $\mathrm{dkk} .{ }^{16}$ memberikan hasil sensitivitas audiometri nada murni sebesar $50 \%$ dan spesifisitas 78\%. Hasil yang serupa juga didapatkan dari penelitian Petticrew dan Sharp, ${ }^{17}$ Halloran dkk. ${ }^{16}$ dalam penelitiannya juga menyebutkan terdapathasil sensitivitas audiometri nada murni yang lebih tinggi sebesar 93\% dan spesifisitas 99\% karena menggunakan operator yang terlatih dan pengendalian faktor kegaduhan lingkungan yang baik. Jika dibandingkan dengan pemeriksaan audiometri subjektif lainnya yang umum digunakan untuk pemeriksaan gangguan dengar pada anak adalah kuesioner, uji suara, uji garputala, ataupun behavioral observation audiometry (BOA), maka audiometer skrining medan bebas lebih baik oleh karena pemeriksaan pendengaran dengan mempergunakan kuesioner hanya dapat mengidentifikasi 50\% anak dengan gangguan dengar, uji suara hanya mempunyai sensitivitas $40 \%$ dan spesifisitas $83 \%$, serta uji garputala hanya mempunyai sensitivitas $30 \%$ dan spesifisitas $87 \%$. $^{18,19}$

Tingkat reliabilitas pemeriksaan pendengaran audiometer skrining medan bebas memberikan kesesuaian cukup baik (moderate agreement). Secara statistik tidak terdapat perbedaan bermakna hasil pemeriksaan audiometer skrining medan bebas dengan hasil pemeriksaan audiometri nada murni untuk mendeteksi gangguan dengar pada anak sekolah dasar dengan otitis media $(p=0,302)$.

Berdasarkan hasil penelitian ini menunjukkan audiometer skrining medan bebas cukup akurat dan reliabel untuk mendeteksi gangguan dengar pada anak sekolah, walaupun belum memberikan nilai diagnostik yang baik apabila dibandingkan dengan audiometri nada murni. Untuk keperluan skrining pendengaran diperlukan alat skrining pendengaran yang mempunyai nilai sensitivitas

Tabel 5 Ketidaksesuaian Hasil Pemeriksaan berdasarkan Diagnosis

\begin{tabular}{lccc}
\hline \multirow{2}{*}{ Diagnosis } & \multicolumn{2}{c}{ Hasil Pemeriksaan Pendengaran } & $\begin{array}{c}\text { Jumlah } \\
(\mathbf{n}=\mathbf{1 5})\end{array}$ \\
\cline { 2 - 4 } & $\begin{array}{c}\text { Audiometri Skining } \\
\text { Medan Bebas }\end{array}$ & Audiometri Nada Murni & 10 \\
\hline OME ADS & Terganggu & Normal & 2 \\
OME AS & Normal & Terganggu & 2 \\
OME AD & Normal & Terganggu & 1 \\
MT perforasi AS & Normal & Terganggu & \\
\hline
\end{tabular}


tinggi ( $>90 \%$ ) dan juga reliabilitas baik (indeks Kappa $>0,4)$, maka audiometer skrining medan bebas dapat dipakai sebagai pengganti audiometri nada murni untuk kepentingan skrining pada anak usia sekolah.

Pada hasil pemeriksaan audiometer skrining medan bebas dan audiometer nada murni terdapat ketidaksesuaian. Semua penderita dengan otitis media unilateral pada pemeriksaan audiometer skrining medan bebas memberikan hasil normal, tetapi didapatkan gangguan pendengaran pada pemeriksaan audiometer nada murni. Keadaan ini menunjukkan bahwa audiometer skrining medan bebas tidak dapat digunakan untuk mendeteksi gangguan dengar unilateral pada penderita otitis media unilateral dan ini merupakan kelemahan alat ini. Fenomena ini terjadi oleh karena stimulus diberikan secara free field (terjadi cross hearing) dan ambang dengar yang diambil adalah ambang dengar telinga yang lebih baik (better ear). Untuk mengantisipasinya maka pada saat pemeriksaan dengan menggunakan audiometer skrining medan bebas, anak dengan gangguan dengar unilateral biasanya tidak dapat melokalisir stimulus yang diberikan. Para klinisi perlu mencurigai gangguan dengar unilateral apabila penderita mengalami disorientasi suara ketika dilakukan pemeriksaan. Prevalensi gangguan dengar unilateral anak usia sekolah hanya sebesar $0,1-5 \%,{ }^{20}$ sehingga pada saat dilakukan pemeriksaan audiometer skrining medan bebas dan dicurigai ada gangguan dengar unilateral maka sebaiknya subjek tersebut dapat kita kategorikan sebagai yang tidak lulus skrining sehingga harus segera dirujuk untuk memperoleh pemeriksaan diagnostik lebih lanjut.

Simpulan, audiometer skrining medan bebas mempunyai tingkat ketepatan yang sama dengan audiometer nada murni untuk digunakan dalam mendeteksi gangguan dengar pada anak sekolah dasar yang menderita otitis media. Audiometer skrining medan bebas memiliki kelemahan dalam mendeteksi gangguan dengar unilateral.

Berdasarkan uji diagnostik pada penelitian ini maka audiometer skrining medan bebas dapat dipakai sebagai alat skrining/deteksi dini fungsi pendengaran bagi anak sekolah dasar. Penelitian lebih lanjut pada populasi berbeda serta gangguan dengar yang diakibatkan penyakit lainnya perlu dilakukan untuk menunjang aplikasi audiometer skrining medan bebas yang lebih luas.

\section{Daftar Pustaka}

1. Bolajoko OO, Abayomi OS, De WS. The need for standardization of methods for worldwide infant hearing screening: a systematic review. Laryngoscope.
2008;118:1830-6.

2. World Health Organization. Regional office for South East Asia. Situation review and update on deafness, hearing loss and intervention programmes. Proposed plans of action for prevention and alleviation of hearing impairment in countries of the south east asia region. New Delhi: WHO; 2007.

3. Bolajoko OO, Valerie EN. Global burden of childhood hearing impairment and disease control priorities for developing countries. Lancet. 2007;369:1314-7.

4. WHO-SEARO. Situation review and update on deafness, hearing loss and intervention programmes. New Delhi: WHO-SEARO; 2007.

5. Djelantik B. The magnitude and etiology of hearing impairment in the general population of bandung area, indonesia. Preliminary Report of a WHO-PDH Multicentre Study. New Delhi: WHO-SEARO; 2002.

6. Maharjan M, Bhandari S, Singh I, Mishra SC. Prevalence of otitis media in school going children in Eastern Nepal. Katmandu University Med J. 2006;4(16):479-82.

7. Williams CJ, Coates HL, Pascoe EM, Axford Y, Nannup I. Middle ear disease in aboriginal children in Perth: analysis of hearing screening data, 1998-2004. Med J Australia. 2009; 190:598-600.

8. Ratunanda SS. Tingkat gangguan pendengaran konduktif pada anak kelas satu SD tersangka otitis media efusi di beberapa sekolah dasar kota Bandung [tesis]. Bandung: Universitas Padjadjaran; 2003.

9. Yusuf PA. Perancangan dan implementasi audiometer skrining medan bebas untuk anak balita [tesis]. Bandung: Institut Teknologi Bandung; 2009.

10. Clark JL, Newton V. Providing diagnostic audiology services in economically challanged regions. Dalam: McPherson B, Brouillette, penyunting. Audiology in developing countries. New York: Nova Science Publisher; 2008. hlm. 113.

11. Georgalas C, Xenellis J, Davilis D, Tzangaroulakis A, Ferekidis E. Screening for hearing loss dan middle-ear effusion in school-age children, using transient evoked otoacoustic emissions: a feasibility study. J Laryngol Otol. 2008;122(12):1299-304.

12. Grundfast KM, Siparsky NF. Hearing loss. Dalam: Bluestone CD, Stool SE, Alper CM, Arjman EM, Casselbrant ML, Dohar JE, dkk, penyunting. Pediatric otolaryngology. Philadelphia: Saunders; 2003. hlm. 306-37.

13. Langan LA, Sockalingam R, Caisie R, Corsten G. Occurrence of otitis media and 
hearing loss among first nations elementary school children. Can J Speech-Languange Pathol Audiol. 2007;31(4):178-85.

14. Roeser RJ, Valente M, Dunn HH. Audiology diagnosis. New York: Thieme; 2007.

15. Pusponegoro HD, Wirya IGNW, Pudjiadi AH, Bisanto J, Zulkarnain SZ. Uji diagnostik. Dalam: Sastroasmoro S, Ismael S, penyunting. Dasar-dasar metodologi penelitian klinis. Edisi ke-2. Jakarta: CV Sagung Seto; 2002. hlm. 166-83.

16. Halloran DR, Hardin JM, Wall TC. Validity of pure-tone hearing screening at wellchild visits. Arch Pediatr Adolesc Med. 2009;163(2):158-63.

17. Petticrew M, Sowder A, Lister-sharp D. False-negative results in screening programs. Medical, psychological, and othet implications. Int J Technol Assessment Health Care. 2001;17(2):164-70.

18. Harlor Ad Jr, Bower C. Hearing assessment in infants and children: recommendations beyond neonatal screening. Pediatrics. 2009;124(4):1252-63.

19. Boatman DF, Miglioretti DL, Eberwein C, Alidoost M, Reich SG. How accurate are bedside hearing tests? Neurology. 2007;68:1311-4.

20. Lieu JE. Speech-language and educational consequences of unilateral hearing loss in children. Arch Otolaryngol Head Neck Surg. 2004;130(5):524-30. 